\title{
El estilo ensayístico en dos obras de escritoras peruanas del siglo XX: Así hicieron las mujeres el Perú de Judith Prieto y Cinturón de castidad. La mujer de clase media en el Perú de Maruja Barrig
}

\author{
Sonia Luz Carrillo Mauriz \\ Universidad Nacional Mayor de San Marcos \\ soniluz@gmail.com
}

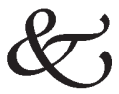

Resumen

En el Perú existe una apreciable tradición ensayística tanto en su vertiente literaria, política, filosófica, socio cultural, así como en otros ámbitos. En anterior investigación, acerca del sujeto femenino y su doble relación con el ejercicio de la palabra escrita y la discursividad política, hallé textos de naturaleza ensayística de escritoras mujeres que exponen posturas frente a hechos sociales y culturales a través de una prosa breve que, sin pertenecer a la narrativa ni a la poesía, ostentan nítidamente su naturaleza creativa. Considerando que este aporte no había sido puesto de relieve, este estudio se propone la observación de textos de estilo ensayísto producidos por escritoras peruanas centrándose en las obras Así hicieron las mujeres el Perú, de Judith Prieto (1965) y Cinturón de castidad. La mujer de clase media en el Perú, de Maruja Barrig (1979).

Palabras Claves: Ensayo, género, sujeto femenino, ensayo peruano.

\begin{abstract}
In Peru there is an appreciable essayistic tradition both in its literary, political, philosophical, socio-cultural and other fields. In previous research, about the female subject and its double connection with the exercise of the written word and the political discourse, I found texts essayistic nature of women writers to expose positions on social and cultural events through a brief prose without belonging to narrative or poetry clearly flaunt their creative nature. Whereas, this contribution had not been highlighted, the study aimed to observe essayistic style
\end{abstract}


texts produced by peruvian writers this time focusing on the works So women did Peru, of Judith Prieto (1965) and Chastity belt. Middle-class women in Peru, of Maruja Barrig (1979).

Keywords: Essay, gender, peruvian essay.

\section{Introducción}

Definido como "escrito, generalmente breve constituido por pensamientos del autor sobre un tema, sin el aparato ni la extensión que requiere un tratado completo sobre la misma materia" (RAE), lo que interesa para el presente estudio es observar el ensayo en su carácter de género híbrido capaz de combinar hechos observados con la exposición, desde una perspectiva personal de la autora u autor y su voluntad de generar, a partir de variados recursos, el diálogo o la provocación a un lector o lectora implícitos no especializados, en este caso, en temas de 'genero', entendido este 'género' en tanto discurso acerca de los atributos socio culturales que caractirizan o definen a hombres y mujeres.

En torno al género ensayo se ha señalado su capacidad de armonizar textos. Al analizar un conjunto de ensayos de Bárbara Jacobs, Concepción Bados-Ciria (200: 314) dirá "(por un lado) el ensayo le permite incidir en una encrucijada de géneros que mezclan la crónica, la experimentación con el lenguaje y las memorias; por el otro, este género propicia una reflexión intimista y personalizada emparentada con la ironía más sutil".

En cuanto a los temas, la libertad rige la labor del ensayista, sin embargo, una vez determinado el tema, el ensayista demarca con claridad los límites entre el texto imaginativo artístico del texto argumentativo basado en la fidelidad a los datos de la realidad. La expresión cuidada y sugerente se coloca al servicio de la verdad ya sea en el campo de la ciencia o de las humanidades o las observaciones prolijas a hechos de la cotidianidad.

Los cambios en la percepción de la mujer y de su ubicación en el mundo social, al par que un nuevo tipo de relación establecido entre hombres y mujeres que ahora se percibe, tienen una larga gestación que ha tenido en la palabra escrita un innegable soporte. Estos cambios sociales y culturales que algunos observan como una de las transformaciones más importantes del siglo XX se han ido expresando, en distintos momentos a través del ensayo, género que concita un renovado interés por su capacidad de producir intercambio de textualidades.

En torno a la especificidad del ensayo se ha señalado que es "un tipo de texto que no se deja definir" (Hernández González: 2005: 7), un texto fruto de la osadía en la defensa de una posición no exenta de belleza - 'el principio del placer' en un texto (Wolf 1984:211) - y apelación a través de metáforas, frases figurativas usadas para la persuación (Ricoeur 2006:61). Con frecuencia, el en- 
sayo adopta el tono de afirmaciones aforística (Sontag 2008:389) en la presentación de temas abiertos a la polémica, mientras las apostillas y citas permiten avisorar las lecturas y la comunidad de intereses que animan a su autora u autor. $Y$ es que el ensayo es una forma de escritura "comprometida con la época de su creación, determinada por una situación cultural y de la comunidad para la que surge puesto que ambos elementos dan ojos al ensayista y contribuyen a cambiar las formas de pensamiento". (Hernández 2005: 9)

En el Perú existe una apreciable tradición ensayística tanto en su vertiente literaria, política, filosófica, socio cultural, así como en otros ámbitos. En anterior investigación, acerca del sujeto femenino y su doble relación con el ejercicio de la palabra escrita y la discursividad política, hallé textos de naturaleza ensayística de escritoras mujeres que exponían sus observaciones ante diferentes temas través de una prosa breve que, sin pertenecer a la narrativa ni a la poesía, ostentan nítidamente su naturaleza creativa. Por esta razón, el estudio partió de la siguiente Hipótesis: A pesar de constituir un género que posee en el país una apreciable tradición, hasta el momento no se cuenta con un estudio acerca de los ensayos producidos por mujeres ni se ha registrado e interpretado sus aportes estilísticos.

Fueron objetivos específicos del estudio: la ubicación y registro de un conjunto de ensayos con perspectiva de género difundidos en diversos medios impresos peruanos, producidos y difundidos entre las décadas 60' y 70', a fin de identificar sus rasgos generales e interpretar su intereacción con el contexto en el que surgieron.

\section{El método y los hallazgos}

Para el presente estudio la opción metodológica fue la investigación documental, consulta y lectura crítica de documentos y materiales bibliográficos, pertinentes al tema propuesto.

El trabajo ha permitido ubicar las caracterísitcas más importantes de un tipo de escritura de corte argumentativo que, elaborado con gran libertad temática y la armonización intertextual, logra un discurso de notable eficacia comunicativa en el abordaje individual, muchas veces subjetivo - pero diferenciado del texto artístico - de un aspecto de la vida social o cultural en un determinado contexto socio cultural.

En este caso, el estudio se centró en la perspectiva de 'género', en tanto presentación de los atributos socio culturales que caracterizan o definen a hombres y mujeres. Por ello, luego de consultar un corpus variado, teniendo en consideración que se tratara de obras del siglo XX, se determinó la elección de dos obras de autoras peruanas: Así hiciero las mujeres el Perú, de Judith Prieto 
de Zegarra (1965) y Cinturón de castidad, la mujer de clase media en el Perú , de Maruja Barrig (1979).

\section{Análisis, Sistematización}

\section{El género ensayo. Conceptos generales y su expresión en el Perú (siglo $X X)$}

\subsection{El estilo del género ensayo}

El ensayo, "escrito breve constituido por pensamientos del autor sobre un tema, sin el aparato de la extensión que requiere un tratado completo sobre la misma materia" (RAE) es para Díaz Plaja, citado por C. E. Zavaleta (1977:67), un excelente fruto del humanismo europeo porque "desde Montaigne acá, tiene la rigurosa condición de aproximar los temas en que se ocupa, no solo porque los relaciona con nuestro tiempo, sino porque los polariza en el yo pensante del escritor". Un tipo de escritura que señala un punto de madurez cultural en la medida que surge en momentos en que "de adquisición de noticias se da paso a la elaboración personal de ellas".

En el origen del género, es célebre el pasaje de Michel de Montaigne, en sus Essais de 1580, citado por John Skirus ( (2006: 9) :

\footnotetext{
"Esto es puramente el ensayo de mis facultades naturales, y no, en absoluto de las adquiridas; y quienquiera que me sorprenda en ignorancia nada ha de hacer contra mì, pues difícilmente sería yo responsable por mis ideas frente a los demás, yo que no soy responsable ni estoy satisfechos por ellas ante mí mismo. A quienquiera que busque el conocimiento, séale permitido pescarlo donde éste habite; no hay nada que yo profese menos. Estas son mis fantasías por las cuales intento dar un conocimiento no de las cosas, sino de mí mismo".
}

Desde la Ilustración, quedó más o menos establecida la denominación de ensayo para los textos de tipo argumentativo en los que se presentan opiniones, teorías, hipótesis, etc., mediante una actividad analítica y crítica; textos que exponen una interpretación personal y subjetiva de un tema con una finalidad divulgativa. La temática variada así como las posibilidades textuales combinatorias acogen materias de naturaleza histórica, filosófica, científica, literarias, estéticas, de observación de la vida cotidiana, de aspectos socio culturales, etc.

Existe por tanto

"una amplísima gama de lo que podemos denominar géneros ensayísticos (que) viene a constituir la mitad de la Literatura, una mitad de los discursos no prácticos ni estándares, esto es, de las producciones textuales altamente elaboradas, la mitad no estrictamente artística. El 
hecho de que esa 'mitad' o parte haya recibido muy poca aplicación crítica y, en consecuencia, escasos resultados de categorización, cabe interpretarse no solo como una mera deficiencia o dejadez sino también de una realidad compleja que es justamente en la época contemporánea cuando adquiere una dimensión inocultable" (Aullón 2005: 14)

De la observación del estilo en los textos calificados como ensayo, se desprende que es un tipo de escritura en la que diversos tipos de texto se combinan para crear un todo caracterizado por su eficacia para comunicar un tema elegido en plena libertad. En el ensayo, quien escribe expone su particular posición frente a un tema o conjunto de temas, de manera subjetiva y original. En muchos excelentes ensayos se toman prestadas técnicas de distintos géneros literarios, se recurre al relato, acepta la irrupción de diálogos, formas epistolares o de testimonios orales. A partir de esta consideración es posible indicar - con la cautela del caso- algunas de sus características generales:

El punto de vista personal y la organización sugerente, su capacidad de reflexión autónoma, su capacidad de brindar un aporte nuevo, una mirada enriquecedora a un tema o ámbito de la realidad.es lo que hace interesante o importante un texto ensayístico. Por otro lado, aunque imaginativo, no deja de lado el conocimiento profundo y meditado que permite el paso de la mera información a la interpretación madura y con posibilidades de influir en los cambios de pensamiento. No hay tema vedado para el ensayo, sin embargo, la exposición cumple los requisitos de claridad, propiedad, precisión y concisión.

Acerca de la extensión del ensayo no existen reglas. En algunos casos el tema o la intencionalidad del autor deriva en un texto escueto, en otros pueden ser un conjunto de textos relacionados a un tema. Existen también excelentes ejemplos de la reunión de un conjunto de temas diversos agrupados en libro con un título que los unifique. En el caso peruano podemos citar los Siete ensayos de Interpretación de la realidad peruana de José Carlos Mariátegui.

\subsection{El ensayo en Hispanoamérica}

Según Delia Barreiro Pérez (1996) el ensayo en Hispanoamérica se remonta a la época colonial, pero solo a raíz de la Independencia se perfila como género literario. Para la autora, son dos las corrientes fundamentales del ensayo: la sociológica y la literaria. En lo que respecta al ensayo sociológico, señala que este tiene "su origen en la necesidad de definir el concepto de nacionalidad, en la interpretación del pasado, el mestizaje, el problema del indio, el imperialismo económico, etc. Ilustrando al respecto, Barreiro cita un conjunto de autores que representan una "corriente al servicio de las ideas sociales, políticas, económicas y culturales de los pueblos del continente... o a la búsqueda posterior de la propia identidad." 


\begin{abstract}
“Tenemos al argentino Domingo Faustino Sarmiento (1811-1888) y al uruguayo José Enrique Rodo (1871-1917). Destaca fundamentalmente el mexicano José Vasconcelos (1881-1959), que escribe sobre filosofía, estética, historia, pero sus aciertos más notables los logra cuando escribe sobre el tema americano. Tal vez el más conocido de sus ensayos sea "La raza cósmica", donde postula que el futuro de los pueblos estará en manos de una raza arraigada en el trópico americano, ... El dominicano Pedro Henríquez Ureña (1884-1946) trata en su obra de comprender las esencias del americanismo. El argentino Ricardo Rojas (1882-1857) sintetiza en sus escritos el alma de su país e intenta definir el concepto de argentinidad".
\end{abstract}

Más adelante, menciona a los escritores peruanos Manuel Gonzales Prada y sus Páginas Libres y a José Carlos Mariátegui (1895-1930). De este último destaca la atención a los aspectos económicos, sociológicos y políticos.

Y continúa la referencia a escritores de Hispanoamérica:

"El novelista argentino Eduardo Mallea es el mejor intérprete del sentir argentino; su novela participa de la temática de sus ensayos. El mexicano Leopoldo Zea analiza los problemas generales de Latinoamérica y los específicos de la realidad de su país. El escritor cubano José Antonio Portuondo se adentra en la especulación sobre la sociología de la cultura y de la literatura. Las venas abiertas de América Latina es un ensayo del escritor uruguayo Eduardo Galeano publicado en 1971. (...) el poeta y ensayista Octavio Paz analiza la idiosincrasia del mexicano en "El laberinto de la soledad”, y en "El arco y la lira”, la teoría de la expresión poética. Sus libros "Las peras del olmo" y "Cuadrivio" son colecciones igualmente de ensayos literarios."

Por su parte, para Skirius (2006: 17),

"Confesarse, persuadir, crear arte, informar: de estos cuatro impulsos básicos del ensayo hispanoamericano del siglo XX, el último - el informativo - ha producido una serie de radiografías acerca de varias culturas nacionales... la metáfora médica implica una objetividad científica, pero a menudo la interpretación presupone más bien valores subjetivos".

Entre los ensayistas que "intentan una interpretación total de sus naciones" ubica a José Carlos Mariátegui con los Siete ensayos... y al mexicano Octavio Paz con El laberinto de la soledad. Más adelante, establece también un paralelo entre Paz y Sebastián Salazar Bondy con su ensayo Lima, la horrible.

"En su ensayo neobarroco Lima la horrible Sebastián Salazar Bondy ha tratado de hacer, con la ciudad capital del Perú, llena de tradición colonial española, lo que Paz hizo con México en su conjunto El laberinto de la soledad. Salazar Bondy añade también la tesis de Mariátegui acerca del carácter opresivo de la clase dirigente colonial; recrea así un tono 
de J'accuse, reminiscente de las diatribas de González Prada" (Skirius 2006: 18-19).

El ensayo en América hispana del siglo XX tiene en el escritor argentino Ernesto Sábato uno de sus más notables cultores: Heterodoxia (1953), Apologías y Rechazos (1979); La resistencia (2000), Antes del fin, su obra de 1998, o España en los diarios de mi vejez de 2005.

En el caso de las mujeres, la escritora argentina, directora de la emblemática revista Sur, Victoria Ocampo, realiza en su obra La mujer y su expresión (1936) una de las reflexiones más agudas acerca de la marginación de las mujeres en el contexto patriarcal y sobre su dificultosa relación con la cultura moderna, las dificultades que supone configurar una expresión propia desde las mujeres. (Citada por Alicia Salomone 2006: 69). El género ensayístico se encuentra además en Lawrence de Arabia y otros ensayos (1951), Virginia Woolf en su diario (1954), Habla el algarrobo (Luz y sonido) (1959) y Tagore en las barrancas de San Isidro (1961), entre otras obras.

Notable escritora, poeta, narradora y ensayista es también la mexicana Rosario Castellanos, obras como Sobre cultura femenina (1950), La novela mexicana contemporánea y su valor testimonial (1966), La corrupción (1970), Mujer que sabe latín (1973), El uso de la palabra (1974) y El mar y sus pescaditos (1975) exponen, a la vez que su sólida formación intelectual, el vigor de su pensamiento original.

\subsection{El ensayo o el estilo ensayístico en el Perú}

El ensayo como género de escritura no ha tenido en el Perú hasta el momento una atención específica salvo el artículo, ya mencionado, de Carlos Eduardo Zavaleta (1977), que analiza la presencia del ensayo entre 1950 y 1975 . En este trabajo Zavaleta trae a colación las dificultades para categorizar los textos como ensayos. Se apoya en la aseveración de Díaz-Plaja en tanto este sería un paso de la adquisición de noticias a la elaboración personal.

\footnotetext{
"a la hora de preguntar por nuestros ensayistas solemos recordar con orgullo a autores de tesis doctorales y monografías universitarias (donde lo único personal se da en la página final de 'conclusiones'), o de cultores de discursos académicos, a los que somos tan proclives, y aun de artículos periodísticos, forma que originalmente han tomado no pocos de nuestros 'ensayos'. Así, ¿a quién va a extrañarle que yo mencione páginas adelante a varios ensayistas inauténticos, pero valiosos en la historia intelectual del país?” (Zavaleta 1977: 68)
}

El notable narrador y maestro sanmarquino afirma categórico que en el Perú "de modo firme y directo el ensayo se conecta con la historia de las ideas". El periodo que abarca su observación se inicia con la etapa de la postguerra, 
etapa que permitió "que se abriesen ventanas políticas y culturales en el país" así como nuevas ideas y nuevos libros "con las últimas corrientes filosóficas, científicas y artísticas de Europa y Estados Unidos”.

En ese contexto, señala el impacto de la tendencia ideológica existencialista, menciona a Francisco Miro Quesada hablando sobre Sartre y a Alberto Wagner Reyna escribiendo sobre Heidegger. También a historiadores que vuelcan su mirada al país en un certamen peruanista celebrado con ocasión del IV Centenario de la fundación de la Universidad de San Marcos, con la participación de Raúl Porras Barrenechea, Jorge Basadre, Luis E. Valcárcel, entre otros. Dirá el maestro, "Nunca antes los alumnos universitarios de entonces habíamos visto tal despliegue de historiadores, filósofos, sociólogos, y arqueólogos, si bien, por desgracia, faltaban en la lista literatos y artistas" (1977: 69).

Entre los textos de corte ensayístico de los primeros años de la década de los 50' menciona Tempestad en los Andes, de Valcárcel, Mito, tradición e historia del Perú de Raúl Porras. Dedica luego una larga remembranza de hechos históricos y de distintos personajes que tuvieron protagonismo en ellos.

El maestro Zavaleta descubre dos perfiles atendiendo al tema "por debajo de la progresiva revelación del punto de vista del autor": Una línea peruanista y otra de tema libre.

"El primero de ellos equivaldría a la interpretación del élan históricosocial del país y sus esencias como finalidad mayor del texto (...) el tema peruanista o nacional predomina en texto como Mito tradición e historia en el Perú (1951) y El paisaje peruano, de Garcilaso a Riva Agüero (1955) de Porras; Vocación y destino de Hispanoamérica (1954) de Wagner Reyna; El inca Garcilaso, clásico de América (1959) de José Durand; Lima la horrible (1956) de Sebastián Salazar Bondy; El Perú, retrato de un país adolescente (1963) de Luis Alberto Sánchez; La serpiente de oro o el río de la vida (1965) de Alberto Escobar; ¿Existe una filosofía en América Latina? (1968) de Augusto Salazar Bondy y el "Prólogo" a las Conversaciones Basadre-Macera (1974) de Pablo Macera. Tales textos, en efecto, son verdaderos ensayos en que la impronta personal domina los materiales adquiridos y en que hay una postulación final de país o mirador peruano desde el cual se otea el horizonte latinoamericano y mundial" (Zavaleta 1977:72).

Entre los antecedentes de la línea peruanista el autor cita a Elogio del inca Garcilaso (1916) de Riva Aguiero; Siete ensayos de interpretación de la realidad peruana (1930) de Mariátegui; Perú, problema y posibilidad (1931) de Basadre; Vida y pasión de la cultura en América (1935) y !Existe América Latina! (1945) de Sánchez; Tempestad en los Andes (1937) de Luis E. Valcárcel y El inca Garcilaso de la Vega (1945) de Porras.

En el segundo caso, que "depende de la elección y la sensibilidad del autor", las características se centran "en la armonía formal y el planteamiento 
intelectual, y quien lo firma no es otro que 'el divagador arbitrario sobre un tema escogido". En esta línea menciona a Primor y esencia del Persiles (1948) de Jiménez Borja; El hombre sin teoría (1959) de Francisco Miró Quesada; y La orgía perpetua (1975) de Mario Vargas Llosa, entre otros.

Pero el ensayo peruano no solo se ha divulgado en libros o revistas especializadas, y por ello Zavaleta dedica un párrafo a los textos difundidos en periódicos. "Queda una mención especial del 'artículo' aparecido en periódicos y revistas... El periodismo peruano es pródigo en artículos que ha sido meollo de fecundas meditaciones", dirá. Y menciona "las plumas de Manuel Seoane, Francisco Miró Quesada, Hernando Aguirre Gamio, Carlos Delgado, Hugo Neira, Ismael Frías, entre los articulistas políticos. Entre los que se dedican al artículo literario o cultural menciona a Sánchez, Luis Jaime Cisneros, José Jiménez Borja, Aurelio Miró Quesada, José Miguel Oviedo, José Durand. (Zavaleta 1977: 73)

No puedo dejar de anotar que en este extenso recuento de escritores que han dado a sus textos la calidad o el estilo de ensayos, el maestro obvió los nombres de mujeres escritoras, salvo una mención a Nelly Festini, en tanto educadora y a Martha Hildebrandt, como linguiista. No obstante, ahora reconocemos la existencia y labor -desde el remoto antecedente de la franco-peruana Flora Tristán- de casos notables de narradoras y periodistas, a la vez que autoras de textos, considerados 'ensayo', según los mismos criterios usados para el señalamiento de la obra de sus contemporáneos.

El ensayo en el Perú a lo largo de la segunda mitad del siglo XX y hasta nuestros días, tiene en Mario Vargas Llosa uno de sus más altos exponentes. Imposible no citar, por ejemplo, su "Carta de batalla por Tirant lo Blanc" Prólogo a la novela de Joanot Martorell (1969); García Márquez: historia de un deicidio (1971); Historia secreta de una novela (1971); La orgía perpetua: Flaubert y Madame Bovary (1975); Entre Sartre y Camus, ensayos (1981); Contra viento y marea, tres volúmenes de 1983, 1986 y 1990. La suntuosa abundancia, ensayo sobre Fernando Botero (1984); La verdad de las mentiras: ensayos sobre la novela moderna (1990); Un hombre triste y feroz, ensayo sobre George Grosz (1992); Desafíos a la libertad (1994); El lenguaje de la pasión (2001); La tentación de lo imposible, ensayo sobre Los Miserables de Víctor Hugo (2004); El viaje a la ficción, ensayo sobre Juan Carlos Onetti (2008) e incluso El pez en el agua de 1993, en el que reúne memoria, ensayo y autobiografía. 


\section{El estilo ensayístico en la escritura de mujeres. El caso de dos obras de escritoras peruanas del siglo XX: Así hicieron las mujeres el Perú de Judith Prieto y Cinturón de de castidad. La mujer de clase me- dia en el Perú de Maruja Barrig}

\subsection{Ensayo en la escritura de mujeres y reivindicaciones de 'género'. Pioneras}

La consulta a estudios y antologías que tratan del ensayo producido durante el siglo XX y aún de lo que va del presente siglo, rápidamente lleva a la constatación de la escasa o casi inexistente presencia de nombres de mujeres. En el texto de Skirius El ensayo hispanoamericano del siglo XX - publicado en 1981 y con seis reimpresiones hasta el 2006 - se consigna la obra de 33 autores hombres y cuatro mujeres. Ha ocurrido que los criterios canónicos han cumplido, y aun en nuestros días cumplen, una rutina de omisión persistente a pesar de un alto volumen de producción de textos ensayísticos fruto de la labor de las escritoras. Sin embargo, esta situación empieza a cuestionarse al relativizarse los criterios para el establecimiento de los cánones. Al respecto es interesante lo señalado por Mary Louise Pratt:

"La naturalización del canon se ha impugnado en trabajos empíricos de
historiadores literarios que sostienen dos argumentos particularmente
poderosos. Demuestran, en primer lugar, que los cánones son criterios
inestables y cambiantes a través del tiempo, por más que puedan pa-
recer eternos en un momento histórico dado. La obra maestra de hoy,
ayer fue despreciada y probablemente lo volverá a ser mañana. En se-
gundo lugar, al explorar las determinaciones sociales que pesan sobre
los cánones y los procesos de canonización literaria, los investigadores
encuentran líneas de determinación entre los cánones literarios y las
jerarquías sociales",(Esta última tesis se acepta aún desde un punto de
vista tradicionalista. Algunos académicos conservadores reconocen que
los cánones se construyen en torno a intereses e ideologías dominantes,
de clase, género y raza, que ellos suscriben)
Por su parte, los académicos dedicados a relativizar el canon suelen dis-
tinguir dos dimensiones en su quehacer crítico: analizan los cánones,
primero, como estructuras de exclusión y, segundo, cómo estructuras de
valor. El primer paso de esta indagación crítica, y el más sencillo, consiste
en identificar obras que satisfacen los criterios de inclusión en el canon,
pero que están excluidas por razones extraliterarias." (Pratt 2000)

Quien revise los trabajos sobre el ensayo, género reflexivo, puede inclinarse a la consideración de que esta área de la producción textual no ha sido abordada por las mujeres ya sea por innata incapacidad o por las razones de índole socio-cultural que la han afectado negativamente. Sucede además que, como 
señala Pratt, existen obras de mujeres que habiendo sido leídas con profusión en determinado momento, luego son omitidas en las antologías, como son los casos de la argentina Juana María Gorrtti, Clorinda Matto, Mercedes Cabello en el Perú y Gabriela Mistral, la poeta chilena reconocida con el Premio Nobel por su trabajo poético.

La autora señala las restricciones sociales que pesan sobre los procesos culturales, entre ellos el "poder de canonizar" corno el acceso a la alfabetización, a la escritura institucionalizada y a los circuitos de la cultura impresa; poder que "está en manos de las instituciones académicas, que son de las más excluyentes que existen." Sin embargo, recuerda que en el contexto de los cambios experimentados por la cultura occidental a partir de fines de los años 60' y el desarrollo del feminismo y los movimientos estudiantiles, las estructuras canónicas han venido sintiendo el impacto de las batallas democratizadoras y nuevas perspectivas críticas.

La revisión que Pratt realiza de las antologías que "canonizan” a los autores de ensayo, es de gran importancia y amerita citarla en extenso:

"Las antologías, esos grandes espejos del canon, son, en el caso del ensayo latinoamericano, verdaderos monumentos a la intelectualidad masculina, regidos por una docena de nombres ampliamente conocidos y muy valiosos: Bello, Echeverría, Sarmiento, Montalvo, González Prada, Hostos, Martí, Rodó, Henríquez Ureña, Vasconcelos, Mariátegui, Martínez Estrada, Arciniegas, Reyes, Picón-Salas, Zea, Paz, Anderson, Imbert. Una breve revisión de las antologías de ensayo latinoamericano disponibles en la biblioteca de la Universidad de Stanford (Skirius, 1981; Earle et. al, 1973; Vitier, 1945; Rey; 1985; Ripoll, 1966; Urello, 1966; Guillén, 1971; Foster, 1983) reveló muy pocas excepciones al monopolio masculino. Sólo Gabriela Mistral aparece entre los veintiséis autores recogidos en una antología de ensayos del siglo XX (Skirius, 1981) mientras que la puertorriqueña Concha Meléndez es autora del fragmento más corto de una antología de ensayistas contemporáneos (Guillén, 1971). Una historia general del ensayo latinoamericano (Earle et al.) menciona brevemente a Meléndez, a su compatriota Margot Arce y a la argentina Victoria Ocampo."

Más adelante, se detiene en el caso del crítico estadounidense David W. Foster quien "plantea el tema de la ensayística de las mujeres en un breve capítulo final dedicado a los Testimonios de Victoria Ocampo, cuya principal característica -en opinión del crítico- es la evidente insignificancia de los temas abordados." Y con justicia destaca "Llama la atención que el crítico eligiera analizar los Testimonios, que son escritos autobiográficos, cuando Ocampo es autora de muchas páginas que, sin lugar a duda, son ensayos". 
¿Por qué estos textos no se han abordado en estudios críticos, ni en programas de cursos o en las antologías del ensayo latinoamericano? En uno de esos ensayos, escrito en tres partes y titulado La mujer y su expresión, 1936, Ocampo ofrece un posible diagnóstico de las causas de su propia exclusión:" Creo-escribe la argentina-que desde hace siglos toda conversación entre el hombre y la mujer, apenas entra en cierto terreno, empieza por un 'no me interrumpas' de parte del hombre. Hasta ahora el monólogo parece haber sido la manera predilecta de expresión adoptada por él" (Pratt 2000).

A contrapelo de lo observado por Ocampo en 1936, Pratt advierte importantes antecedentes a fin de establecer "un corpus amplio, continuo y muy poco estudiado":

“... es evidente que las mujeres intelectuales no sucumbieron a las resonancias del "No me interrumpas" de que Ocampo hablaba. ... Las intelectuales criollas crearon un corpus textual que llamaremos el "ensayo de género", una tradición de escritura que se desarrolló de manera paralela al ensayo de identidad. Es una literatura contestataria que se propone "interrumpir el monólogo masculino" -por decirlo en palabras de Victoria Ocampo- o al menos confrontar la pretensión masculina de monopolizar la cultura, la historia y la autoridad intelectual. Como sucede con el ensayo de identidad, el corpus completo del ensayo de género comprende cientos de libros y miles de páginas. A manera de ejemplo, podemos mencionar algunas obras de las escritoras más conocidas (ver Marting, 1987, 1990): La mujer (1860), de Gertrudis Gómez de Avellaneda, Emancipación moral de la mujer (1858), de Juana Manso, Influencia de la mujer en la sociedad moderna (1874), de Mercedes Cabello de Carbonera, Las obreras del pensamiento en América Latina (1895), de Clorinda Matto de Turner, La mujer en la sociedad moderna (1895), de Soledad Acosta de Samper, El feminismo y la evolución social (1911) y Socialismo y la mujer (1946) de Alicia Moreau de Justo, ¿A dónde va la mujer? (1934) de Amanda Labarca Hubertson, Influencia de la mujer en la formación del alma americana, (1930/ 1961) de Teresa de la Parra, La mujer y su expresión (1936) de Victoria Ocampo, Hacia la mujer nueva (1933) de Magda Portal, Sobre cultura femenina (1950) y Mujer que sabe latín (1973) de Rosario Castellanos. De ninguna manera propongo establecer un nuevo canon a partir de estas obras, tan sólo presento un corpus amplio, continuo y muy poco estudiado."

Finalmente, concluye abogando por que el debate en torno al género, "en el que participaron hombres y mujeres de las más diversas posiciones ideológicas" ingrese a la historia intelectual de América Latina con el mismo peso del debate sobre la identidad y que se reconozca su "importancia capital dentro del proceso de autocreación y autoconocimiento de las sociedades latinoamericanas". 


\subsection{Estilo ensayístico en la obra Así hicieron las mujeres el Perú de Judith Prie- to. Un ensayo histórico}

Publicado en 1965, luego de haber merecido un premio en el Concurso Elvira García y García sobre la "Participación de la mujer en la gesta de la emancipación nacional", organizado por el Consejo Nacional de Mujeres del Perú, en 1964, Así hicieron las mujeres el Perú de la doctora Judith Prieto de Zegarra, profesora universitaria de Historia y Educación, tiene un conjunto de las características señaladas para la consideración de un texto en estilo ensayístico.

En el Prólogo, el historiador Carlos Daniel Valcárcel, sitúa el aporte de Prieto, en primer lugar como "Una investigación sobre la contribución de la mujer peruana desde la precursora época borbónica - lapso decisivo para entender el Perú actual". En el siguiente párrafo, utiliza el término ensayo y, como veremos más adelante, es una categorización ajustada a varios de los aspectos de la obra:

"Su ensayo, susceptible de aumentar mediante futuras indagaciones sobre la contribución femenina en nuestra historia, representa principalmente un examen de movimientos específicamente peruanos que propiciaron la secesión del Imperio colonial hispánico, la reivindicación independentista. Su tema se desarrolló concomitantemente a la gesta de nuestros próceres en diversos momentos y lugares del país desde la selva hasta la costa" (Prieto 1965: 3).

La obra, que en un conjunto de breves apuntes nos descubre la vida y actitudes heroicas de muchas mujeres en la lucha independentista, lleva una Introducción donde advierte:

"En la gran epopeya del suelo peruano, la mujer siente las mismas angustias del varón, sufre tormento al ver a los suyos sometidos a los crueles tratos de los amos de entonces y rebelándose contra ese sistema de vida, brinda la más decidida colaboración, la que se convierte en uno de los más poderosos determinantes del éxito de la empresa emancipadora" (Prieto 1965: 13).

Más adelante, en una brevísima nota, "La Participación de la mujer peruana en los levantamientos del siglo XVIII", señala:"Los documentos históricos, los críticos, así como los historiógrafos dan poca importancia a la actitud del elemento femenino en muchas oportunidades". Cita luego una opinión del director del Museo Histórico Regional de Ayacucho, César Prado:

"Los enfoques históricos resultan unilaterales e inconclusos cuando se olvida la contribución de la mujer en el proceso histórico, la cual es patente y fecunda. No se alcanza a comprender cómo se quiere varonizar la Historia, como si la mujer no tuviese capacidad de creación en el dolor y la esperanza del quehacer colectivo". 
A rescatar del olvido a estas mujeres se orientan los textos de Prieto. Por ejemplo, iniciando la obra, se presenta, bajo el título de "Ana de Tarma" (1748), la figura de una mujer que participó en la rebelión de Juan Santos, en las zonas de Jauja, Tarma y Chanchamayo:

"Sobre Ana de Tarma sabemos poco, ya que hay solo menciones de ella que la presentan como capitana de un cuerpo de guerrilleras que actuaban al lado de sus familiares y bajo las órdenes generales de su caudillo. Ana de Tarma, según las versiones, dirigió a sus huestes femeninas en el combate del Río de la Sal, frente a las fuerzas del español Benito Troncoso, de igual manera en el combate de Nijandaris, que constituyó un desastre para las tropas realistas.

En notas de campaña enviadas al virrey del Perú, el Marqués de Villagarcía, se da cuenta de lo siguiente:

"En segundo avance las tropas del capitán General Troncoso, llegaron el 22 de octubre de 1747 a la hacienda de Oxabamba, ordenando fuera respetada del saqueo y el 23, tropas de reconocimiento informaron a Troncoso que de la confesión arrancada a un chuncho, se daba a conocer de la existencia de una compañía de guerrilleras capitaneadas por una Ana de Tarma; en este grupo había cincuenta y dos mujeres, dos de ellas eran viudas y que además habían tomado parte en el asalto de Quimiri" (Prieto 1965:16)

A pie de página, Prieto señala como fuente "Manuscritos"- Tomo 250, Fol. 303 y 332 - en Biblioteca Nacional, Sección Investigaciones, Consignado "Juan Santos", demostrando el rigor documental en el uso de las fuentes.

En la nota dedicada a "Micaela Bastidas y Puyucagua", la célebre heroína esposa de Túpac Amaru, el texto tiene de relato, cita de fuentes como el Archivo de Indias de Sevilla, Archivo General de Indias de la Audiencia del Cuzco, manuscritos de la Biblioteca Nacional de Lima, etc., incluye, además, un fragmento de una versificación que ayuda a la descripción de la heroína.

"De su aspecto físico se sabe que era de mediana estatura, de cara algo redonda y según el escritor cuzqueño Juan de la Cruz Salas, ‘Tenía la frente alta y ancha con la serenidad del mar, los ojos negros como una noche serrana, nariz aguileña y caída sobre labios gruesos, la cabellera larga y negra extendida en la espalda..." y este mismo autor le dedica emocionado estos versos que me atrevo a insertar:

"Mujer bella como ninguna / Y cual un ángel con mejillas de Luna; /Tiene la hondura azul del cielo en las pupilas/ La floración de una rosa en los labios; la blancura del granizo en los dientes / y en uñas manos la blancura de los lirios de Abril'.

Luego presenta, junto a su espíritu patriótico, variadas aptitudes de Micaela Bastidas, su magnanimidad mostrada en los "Bandos" a los que Prieto ha accedido. Su capacidad de organizadora y estratega también son señaladas con minuciosidad: 
"Esta extraordinaria mujer formó parte del movimiento integrando el 'Consejo de los cinco' y sus opiniones valiosas demostraron su clara inteligencia, su sentido innato de la estrategia, su gran conocimiento de toda la zona que ella en épocas anteriores había recorrido, así como el conocimiento de las necesidades y sufrimientos de la masa indígena que veía en ella a un verdadero ángel tutelar, de igual manera, manifestó gran pericia en la solución de los problemas de abastecimiento, organizó con gran eficacia el servicio de propaganda y comunicaciones a través de veloces indios a manera de chasquis, así como puso en contacto a los caciques para la ayuda de refuerzos militares y el abastecimiento en general”.

El hecho histórico de que la Bastidas sabía leer y escribir en castellano, y que pese a su importante papel, su opinión de atacar el Cuzco fue desoída en el momento crucial, es recordado en la nota:

"La correspondencia que sostuvo con su esposo y sus hijos fue frondosa y sus cartas son expresiones de ternura y cariño familiar; nada había para ella más hondo en sus afectos que su amada Chepe, como le decía a su esposo y al él se dirigía reiteradamente para sugerirle sobre la urgencia de tomar la ciudad del Cuzco, después de la victoria de Sangarara, sin embargo, no se tomó en cuenta esta valiosa opinión y Túpac Amaru procedió con demasiada confianza ante los movimientos del enemigo" (1965: 37).

Derrotada la rebelión, los vencidos son sometidos a severas penalidades entregados a las tropas del "feroz visitador Areche, el cual extremó los más refinados métodos de tortura... las sentencias aplicadas a estos patriotas constituyen una expresión de gran crueldad como otrora sufrieran por su fe los primitivos cristianos en el circo romano" (1965: 37).

El texto histórico se carga de emotividad al relatar los momentos finales de la heroína, luego de transcribir la sentencia de José Antonio de Areche "pena de garrote, cortándosele antes la lengua y luego se le colgará en una horca y luego será descuartizado su cuerpo":

"La crueldad refinada de sus verdugos la hicieron presenciar la muerte de su amado hijo Hipólito, y con el corazón traspasado de dolor al ver el descuartizamiento, presentó la boca al verdugo para que cumpliera la sentencia de cortarle la lengua, luego subió al garrote"; luego, cita una fuente histórica "pero por la delgadez de su cuello que dificultaba la maniobra del torniquete, fue muerta a patadas en el vientre y en el pecho, el cual fue reventado".

El párrafo final se inicia "Al caer la tarde, los restos de Micaela eran expresiones sangrientas de la ferocidad de sus enemigos".

Por el tema de exaltación de la identidad basada en el reconocimiento de más de un centenar de valerosas mujeres que contribuyeron a la emancipación del poder colonial y su conveniente ubicación en el cuadro general de los 
héroes; por la forma personal, por momentos emotiva, y la incorporación de textos diversos a fin de lograr un cambio de pensamiento; por la exposición dinámica de los datos, Así hicieron las mujeres el Perú de Judith Prieto puede ser identificado con todo mérito como un ensayo histórico.

$\mathrm{Si}$, como indica Vicente Cervera (2005: 7), el ensayo es un texto "comprometido con la época de su creación, determinada por una situación cultural y para la comunidad para la que surge...y contribuye a cambiar las formas del pensamiento", Así hicieron las mujeres el Perú de Judith Prieto, cumple con estos requisitos al ser publicado en 1965 , en momentos en que se iniciaba la incorporación en mayor volumen de mujeres a la instrucción universitaria (personalmente, fue el año de mi ingreso a la universidad) y en los años siguientes uno de los combates cultuales más vigorosos fue el de la revaloración del papel de la mujer en la cultura, la sociedad, la Historia.

\subsection{Estilo ensayístico en Cinturón de castidad. La mujer de clase media en el Perú de Maruja Barrig. Ensayo sociológico}

Concluía la década de los años setenta y en 1979, Maruja Barrig publica Cinturón de castidad. La mujer de clase media en el Perú. En la contraportada del libro se lee, "Cinturón de castidad, título que alude al aherrojamiento mental impuesto a la mujer por la ideología dominante, es una radiografía y a la vez un desafío: vincular desde una perspectiva propia la condición femenina al conjunto de problemas que frustran la sociedad nacional. Maruja Barrig saca a la luz en este libro una problemática apenas reconocida en nuestro medio y le abre nuevas vías de esclarecimiento y reflexión”.

La obra se Barrig responde a un contexto internacional y nacional del que es necesario mencionar alguno hechos relevantes. En el caso del Perú, desde octubre de 1968 se vivía una situación nueva para el país. Un gobierno militar desconcierta con medidas como la recuperación de los pozos petroleros en manos de una poderosa transnacional; al año siguiente, se aplica la reforma agraria. Una serie de medidas como el inicio de relaciones con los países - en aquel entonces - socialistas; el ingreso del Perú al Movimiento de Países No Alineados; Reforma de la educación, etc., generaron una atmósfera propicia a profundos cambios culturales estimulados por la ampliación en la difusión de diversas corrientes de pensamiento, como la antes censurada marxista.

El discurso de los textos de variada naturaleza exponen las visiones de sujetos que conceptualizan la ciudad en tanto un tipo de civilización y registran con irreverencia -y muchas veces provocadoramente- nuevas interacciones sociales, étnicas, de género etc. Responden a un "espíritu de ciudad", en el que predominan los frutos de la revolución tecnocientífica y las condiciones que el proceso de modernización entraña. 
Al indagar por quiénes hablan en los textos producidos en los últimos años de los 60' y durante la década de los 70' nos encontramos con enunciadores urbanos de capas medias y bajas enfrentados con "lo establecido", viajeros que vienen y van de una a otra ciudad, mujeres buscando forjar nuestra propia voz. Y, en casi todos, ira por las precarias circunstancias heredadas, malestar, desenfado en la expresión y la ardorosa vocación de cambiar el mundo.

El libro de Maruja Barrig está constituido por una Introducción y cuatro partes a la manera de capítulos. En los primeros tres, una prosa ágil y en muchos casos de tono irreverente, enjuicia mordaz los atavismos en torno a la situación de la mujer en general y de su sexualidad en particular. Los subtítulos son expresivos en su connotación. En el capítulo Uno, por ejemplo, se lee: "De la costilla de Adán, a la esposa sumisa”, “¿De qué sirve ser mujer?”; “Ocupación: su casa"; "La casada, en libertad condicional”; "La exclusión como política"; "La inmundicia moral del divorcio". En el capítulo Dos: "Función política de la continencia"; "Un himen con status"; entre otros similares.

El tono personal está fuertemente marcado en los tres primeros capítulos en los que informaciones académicas se entretejen con reflexiones particulares. Expresivo del estilo ensayístico son los primeros párrafos en los que la autora relata un hecho autobiográfico.

Expone sus críticas al papel de la iglesia que "transmitió un código estricto de comportamiento sexual que impuso penas más severa a medida que éste se alejara del paradigma de la Virgen María”. Así, Barrig realiza una relectura de textos bíblicos:

"La inferioridad de la mujer fue evidente desde su creación: para ella bastó la costilla del hombre; su vanidad y su desobediencia al caer en la trampa que le tendió la serpiente condicionarían su futura fama de torpeza, escasa previsión y agente del demonio" (Barrig 1979:16).

La distinta valoración entre hombres y mujeres se resalta en textos en los que la voluntad femenina es simplemente obviada:

\footnotetext{
"manso recurso a las necesidades de bíblicos personajes. Como Abraham, quien antes de nacer Isaac, llevó a Sara a Egipto escapando de una mala situación económica y le sugirió que se hiciera pasar por su hermana, ya que por ser ella hermosa, sus vidas no correrían peligro y ganarían los favores del Faraón. Fue cierto. El Faraón, atraído por los encantos de Sara la llevó a su casa y estuvo con ella... o Lot, que visitado por los ángeles quiere aplacar con sus propias hijas los apetitos de los sodomitas y les dice: 'He aquí que tengo dos hijas que no han conocido varón (es decir que son vírgenes); os las sacaré afuera si os place y haréis con ellas cuanto bien os pareciere pero no le hagan nada a estos varones' (Génesis:20) (Barrig 1979:17).
} 
A través de los tres primeros capítulos, temas como la escasa o nula o deficiente educación impartida a las mujeres, la carencia de medios para la realización personal, las dificultades que enfrentan las mujeres talentosas en los diferentes ámbitos en los que había empezado tímidamente a incursionar y las fuertes represiones que la auto saboteaban, son presentados con una prosa notable por su humor y causticidad. Pero el tema recurrente es el de la sexualidad reprimida e insatisfactoria:
"Una vez que la mujer de la pequeña burguesía aseguraba su porvenir mediante el matrimonio, la represión de su sexualidad impuesta desde la infancia, su desconocimiento de las más mínimas reglas de la relación sexual y su temor al desamparo económico la resignaban a sus frustra- ciones sexuales, y a lo que Engels llamó 'aburrimiento mortal sufrido en común y que se llama felicidad doméstica'. Para las esposas de hace dos décadas, la relación sexual dentro de la vida conyugal se convirtió en una obligación tediosa que le acarreaba el peligro de una nueva con- cepción y que, privándola de un placer, intuido pero desconocido, la transformó solo en un ente reproductor" (1979: 55-56).

Casi no hay un estereotipo sobre lo femenino tradicional que no haya sido abordado por este importante libro al que se reconoce como una obra que contiene la "historia de la las ideas de dominación de la mujer en el Perú" (Silva 2004). Inclusive los relatos infantiles pasan por la mirada escrutadora de Barrig, como es el caso de sus relectura del cuento infantil de la Cucarachita Martina.

La parte final del libro, o capítulo Cuatro, se encarga de reproducir los testimonios de tres mujeres. La autora explica los criterios para ser convocadas: "Mi intención fue buscar a mujeres que promediaran los treinta años, aquellas que fueron niñas en el ambiente conservador del gobierno del General Odría pero maduraron en el marco del reformismo militar de Velasco. Mujeres de ciudad. Solo dos fueron los requisitos necesarios para seguir sus historias: voluntad confesional y una cierta lucidez y capacidad de reflexión sobre sí mismas." (1979: 84).

En el párrafo final del capítulo que antecede a los Testimonios, la autora advierte:

"Al editar, he limado la versión oral de la secuencia del relato, eliminando historias y detalles que consideré innecesarios, pero he respetado las contradicciones y fluctuantes estados de ánimo de las entrevistadas... esto no significa una alteración en lo fundamental de sus vivencias y reflexiones; antes bien, las modificaciones contribuyeron al desarrollo de la historia, al superarse el temor a la identificación personal. Después de todo, si la pequeña burguesía no tiene historia, por qué las pequeño burguesas han de tener autobiografía". 


\section{Conclusiones}

La realización del estudio permite arribar a las siguientes conclusiones:

De la observación del estilo en los textos calificados como ensayo, se desprende que es un tipo de escritura capaz de combinar diversos elementos creando un todo armónico caracterizado por su eficacia para comunicar un tema elegido en plena libertad. No obstante la diversidad temática, la exposición del punto de vista personal y la organización sugerente, original, es lo que- en líneas generales - caracteriza al texto ensayístico.

La expresión artística de lo ideológico a la par que el insistente tema de la identidad marca notoriamente el ensayo hispanoamericano y peruano. En la lucha ideológica por la independencia y la posterior búsqueda de la propia identidad, los y las escritores(as) intentan una interpretación total de sus naciones y sus culturas.

El ensayo en el Perú ha seguido con frecuencia una línea temática que puede denominarse peruanista y otra orientada a muy diversos temas culturales, sociales y artísticos. El estilo ensayístico con su gran flexibilidad y variedad, permite su exposición a través de diferentes medios, por ello los textos han encontrado su vía de divulgación en libros, revistas de variada naturaleza y el periodismo escrito.

La presencia de las mujeres ensayistas, de larga data y notables frutos no recibió hasta hace algunos años suficiente atención en medios canónicos, sin embargo, la situación ha empezado a cambiar al revisarse los criterios de selección y valoración de las obras y por la labor, fundamentalmente, de las mismas escritoras mujeres.

El estilo ensayístico se encuentra presente en Así hicieron las mujeres el Perú y Cinturón de castidad, la mujer de clase media en el Perú, en ambos casos por la armonización de datos históricos -especialmente en el trabajo de Prieto-y sociológicos - tal es el caso de Barrig- perfectamente documentados, unidos a la visión personal de las autoras que en muchos momentos otorga a la presentación de los mismos el aporte de la expresión de su emotividad frente a los asuntos tratados.

Finalmente, debe señalarse que se impone la necesidad de continuar la indagación en torno al ejercicio de los géneros ensayísticos y su papel en la producción de textos en el país y su aporte al cambio de las ideas y a las transformaciones de la sociedad y la cultura nacional.

\section{Referencias bibliográficas}

AULLÓN, Pedro. (2005) "El género ensayo, los géneros ensayísticos y el sistema de géneros" En: El ensayo como género literario. Murcia, Universidad de Murcia, Servicio de Publicaciones; pp. 14-15. 
BARREIRO PÉREZ, Delia. (1996) "El ensayo en Latinoamérica". En: Letralia Tierra de Letras - Edición N. 7, del 19 de agosto http://www.letralia.com/07/cr01-007. htm\# arriba (10.09.11)

BARRIG, Maruja. (1979) Cinturón de de castidad. La mujer de clase media en el Perú. Lima: Mosca azul, editores.

CERVERA SALINAS, Vicente, HERNÁNDEZ, Belén y ADHUAR María Dolores. (2005) El ensayo como género literario. Murcia: Universidad de Murcia, Servicio de Publicaciones.

HERNÁNDEZ GONZÁLEZ, Belén. (2005) "Prefacio" a El ensayo como género literario. Murcia: Universidad de Murcia, Servicio de Publicaciones, p. 7.

PRATT, Mary Louise, (2000) "No me interrumpas": las mujeres y el ensayo latinoamericano", Debate Feminista (México D.F) Año 11, Vol. 21 (abril) http://porlamatria. blogspot.com/2007/12/no-me-interrumpas-las-mujeres-y-el.html. Consultado el (08.09.11)

PRIETO DE ZEGARRA, Judith. (1965) Así hicieron las mujeres el Perú. Lima: Consejo Nacional de Mujeres del Perú.

REAL ACADEMIA ESPAÑOLA. (1992). Diccionario de la lengua española. Madrid: Espasa Calpe.

SALOMONE, Alicia. (2006) "Virginia Woolf en los testimonios de Victoria Ocampo: tensiones entre feminismo y colonialismo". En: Revista Chilena de Literatura, $N^{o} 69$ Santiago, Universidad de Chile, pp 69-87 http://www.scielo.cl/scielo. php?pid $=$ S0718-22952006000200004\&script $=$ sci_arttext Consultado el 12.09.11.

SILVA SANTISTEBAN, Rocío. (2004) “Cinturón de castidad: 25 años después” En: La Insignia. 21 diciembre. http://www.lainsignia.org/2004/diciembre/cul_043.htm Consultado el 15.07.11.

SKIRIUS, John (Compilador). (2006) El ensayo hispanoamericano del siglo XX. México: Fondo de Cultura Económica.

ZAVALETA, Carlos Eduardo. (1977) "El ensayo en el Perú", 1950-1975. Separata Reunión de Málaga, Servicio de Publicaciones Diputación Provincial de Málaga; pp. 67 -74. 